\section{Pengukuran Stating Point Dimensi Strategi Inovasi Studi pada Pusat Pengembangan Sumber Daya Manusia Aparatur ESDM}

\author{
${ }^{1 s t}$ Hendris Agung Prasojo; ${ }^{2 n d}$ Dian Anggarini; \\ 12 Pusat Pengembangan Sumber Daya Manusia Aparatur
}

\begin{abstract}
The Center for Human Resources development for the ESDM Apparatus is a training institution that provides soft skills and hard skills training, so that PPSDMA can act as an example for other institutions within the Ministry of Energy and Mineral Resources. PPSDMA can adapt to ongoing changes, because it demands continuous innovation so that the organization can be sustainable. The purpose of this research is that PPSDMA can find out the current position of innovation, by measuring the organizational innovation stating point. This study classifies the dimensions and levels of innovation at PPSDMA, Ministry of Energy and Mineral Resources. Each dimension was measured using a questionnaire to employees at PPSDMA. The results of the measurement of the eight innovation strategies are processed quantitatively and statistically and the minimum score is 2.54 and the maximum score is 3.09 . The average score obtained is 2.83 is a sufficient score, which is in the middle position so that PPSDMA is at the stating point as a hopeful innovator. PPSDMA has a spirit of innovation, even though the organization is inclined towards gradual improvement rather than making innovations that change internal business process patterns. Likewise, the organizational approach is still ad hoc and unstructured. PPSDMA should take a systematic view of the core strategic, customer-focused, and focus on the organizational factors needed for the innovation strategy and immediately look for "get it first" opportunities. Take the time to incorporate organizational learning and begin to define processes for continuous innovation.
\end{abstract}

\section{ABSTRAK}

Pusat pengembangan Sumber Daya Manusia Aparatur ESDM merupakan Lembaga pelatihan yang memberikan pelatihan soft skill dan hard skill, sehingga PPSDMA dapat berlaku sebagai contoh bagi institusi lain di lingkungan kementerian ESDM. PPSDMA dapat berdapatasi dengan perubahan yang terus terjadi, karena itu menuntut inovasi yang terus menerus agar organisasi dapat berkelanjutan. Tujuan penelitian ini agar PPSDMA dapat mengetahui posisi inovasi saat ini, melalui pengukuran stating point inovasi organisasi. Penelitian ini mengelompokan dimensi dan tingkat inovasi di PPSDMA, Kementerian Energi dan Sumber Daya Mineral. Masing masing dimensi diukur dengan menggunakan quesioner terhadap pegawai di PPSDMA. Hasil pengukuran delapan strategi inovasi, diolah secara kuatitatif dan statistic dan didapat skor minimal diangka 2.54 dan maksimal 3. 09. Skor rata rata yang didapat 2.83 merupakan skor cukup, yaitu di posisi tengah sehingga PPSDMA ada pada stating point sebagai hopeful innovator. PPSDMA memiliki semangat inovasi, meskipun organisasi condong ke perbaikan bertahap daripada melakukan inovasi yang mengubah pola internal business process. Begitu pula, pendekatan organisasi masih bersifat ad hoc dan tidak terstruktur. PPSDMA sebaiknya mengambil pandangan sistematis dari strategis inti, fokus pada pelanggan, dan fokus pada faktor organisasi yang diperlukan, untuk strategi inovasi dan segera mencari peluang "capai yang mudah lebih dulu". Luangkan waktu untuk memasukkan pembelajaran organisasi dan mulai menentukan proses untuk inovasi yang berkelanjutan.

\section{ARTICLE HISTORY}

Submited: XXXXXXXX Accepted: $X X X X X X X X$ Published: XXXXXXXX

\section{KEYWORDS}

Innovation, Dimension of innovation, Innovation strategy 


\section{Pendahuluan}

Kondisi dunia yang terus berubah secara dinamis, menuntut perubahanan juga di dalam organisasi. Pusat Pengembangan Sumber Daya Manusia Aparatur (PPSDMA) merupakan organisasi non profit yang melaksanakan tugas dan fungsinya sebagai lembaga pelatihan bagi aparatur di lingkungan Kementerian ESDM. Semua organisasi, baik organisasi profit maupun non profit melakukan inovasi untuk mempertahankan kelangsungan hidupnya, organisasi non profit berinovasi untuk menjaga kepercayaan publik sedangkan organisasi profit untuk mendapatkan keuntungan agar organisasinya terus bertahan (Zhang et al., 2019).

Inovasi di PPSDMA dibutuhkan dalam rangka mempertahankan kelangsungan organisasi dan kemampuan bersaing di pasar sesuai pangsa pasar (market share) yang digeluti oleh PPSDMA yaitu jasa pelatihan. Dibutuhkan strategi inovasi yang baik agar organisasi dapat meningkatkan daya saingnya (Ramadani \& Gerguri, 2011).

Strategi inovasi merupakan kerangka pengembangan bisnis untuk masa depan bagi organisasi (Group, 2002), sehingga dibutuhkan pengembangan di sisi peluang, percepatan dalam pengambilan keputusan bisnis, dan pengukuran terhadap dampak terkait dengan daya saing organisasi. Strategi inovasi berfokus pada masa depan yang mengidentifikasi peluang pertumbuhan terobosan, mempercepat keputusan bisnis, dan menciptakan dampak jangka pendek yang dapat diukur dalam konteks visi jangka panjang untuk keunggulan kompetitif yang berkelanjutan.

Tabel berikut ini menunjukan indek kepuasan masyarakat (IKM) dari layanan program kegiatan yang telah dilaksanakan oleh PPSDMA, jika beberapa program bisa mendapatkan predikat sangat baik, diharapkan program kegiatan lainnya bisa mendapatakan predikat yang sama, untuk itu perlu kerja keras dan peningkatan secara terus menerus oleh seluruh aktor di PPSDMA itu sendiri.

\section{Tabel 1. Indek Kepuasan Masyarakat pada Program Kegiatan PPSDMA}

\begin{tabular}{|c|c|c|c|c|}
\hline No & Nama Kegiatan & $\begin{array}{l}\text { Nilai } \\
\text { SKM }\end{array}$ & $\begin{array}{c}\text { Mutu } \\
\text { Layanan }\end{array}$ & $\begin{array}{l}\text { Kinerja Unit } \\
\text { Pelayanan }\end{array}$ \\
\hline 1. & Interactive Content Creation & 3,49 & B & Baik \\
\hline 2. & Interactive Contect Creation Batch II & 3,6308 & A & Sangat Baik \\
\hline 3. & Interactive Contect Creation Batch III & 3,4767 & B & Baik \\
\hline 4. & Interactive Contect Creation Batch IV & 3,4913 & B & Baik \\
\hline 5. & Interactive Contect Creation Batch V & 3,6251 & A & Sangat Baik \\
\hline 6. & $\begin{array}{l}\text { Professional Presentation \& Infographic With Powerpoint } \\
\text { Batch I }\end{array}$ & 3,4958 & B & Baik \\
\hline 7. & $\begin{array}{l}\text { Professional Presentation \& Infographic With Powerpoint } \\
\text { Batch II }\end{array}$ & 3,4533 & B & Baik \\
\hline 8. & $\begin{array}{l}\text { Professional Presentation \& Infographic With Powerpoint } \\
\text { Batch III }\end{array}$ & 3,5664 & A & Sangat Baik \\
\hline 9. & $\begin{array}{l}\text { Professional Presentation \& Infographic With Powerpoint } \\
\text { Batch IV }\end{array}$ & 3,4989 & B & Baik \\
\hline 10. & Videografis for Information and Interactive Media & 3,4409 & B & Baik \\
\hline 11. & Kontent Kreatif untuk Sosial Media & 3,6560 & A & Sangat Baik \\
\hline 12. & Building youre digital mindset (kerjasama ditjen migas) & 3,5539 & A & Sangat Baik \\
\hline
\end{tabular}


Peningkatan inovasi pelayanan dapat meningkatkan kepuasan pelanggan. Pada dasarnya implementasi inovasi pelayanan akan memenuhi harapan kepuasan pada nilai fungsional, sosial dan emosional. (Mahmoud et al., 2018).

Langkah utama untuk meningkatkan inovasi di PPSDMA adalah menemukan stating point (Group, 2002) kondisi inovasi di PPSDMA, sehingga bisa melakukan tindak lanjut berikutnya, yaitu peningkatan inovasi berkelanjutan.

Melalui kerangka strategi inovasi diharapkan ada pengembangan inovasi dalam produk maupun jasa dan model bisnisnya termasuk di organisasi PPSDMA sebagai lembaga pemerintah yang bergerak dalam jasa training dan pengembangan kompetensi (ESDM, 2016)

Strategi inovasi menggabungkan pendekatan non-tradisional dan kreatif untuk inovasi bisnis dengan model konsultasi tradisional, kerangka kerja strategis inovasi akan menginspirasi tim lintas fungsi yang terdiri dari agen perubahan di organisasi, membuat terobosan strategi pertumbuhan, untuk menentukan inovasi layanan dan model bisnis, untuk merangsang hubungan bisnis baru dan untuk memikirkan kembali praktik bisnis saat ini.

Inovasi tergantung pada konteks organisasi, yaitu pada ide ide kreatif yang muncul dan digunakan secara efektif. Membangun dan merawat kondisi organisasi adalah bagian penting dari manajemen inovasi yang melibatkan pekerjaan secara tersetruktur, pengaturan organisasi, pelatihan dan pengembangan, komunikasi organisasi, semua mendukung pada proses pengembangan organisasi melalui manajemen inovasi (Joe et al., 2005).

Organisasi yang mengembangkan strategi baru ketika menghadapi persaingan dan memasuki pasar baru sering menggunakan model bisnis yang baru juga. Mereka mengidentifikasi kesenjangan dalam bagaimana suatu industri diatur, mengejar kesenjangan tersebut dan kemudian menemukan cara untuk mengubahnya menjadi pasar yang menguntungkan (Anderson \& Markides, 2007). Mereka menemukan pelanggan baru ("new whos"), produk atau layanan baru ("new whats") atau cara baru untuk mempromosikan, memproduksi atau mendistribusikan mereka ("new hows") .

Penelitian ini dilakukan di Pusat Pengembangan Sumber Daya Manusia Aparatur. Penelitian ini bertujuan untuk mencari posisi stating point PPSDMA saat ini, sehingga organisasi bisa melakukan strategi inovasi yang berkelanjutan.

Program-program kegiatan yang dilakukan oleh PPSDMA sebagai organisasi ada yang sudah mendapatkan penilaian pengguna dengan predikat memuaskan, namun juga ada beberapa program kegiatan yang pelaksanaan nya masih mendapatkan point yang masih harus ditingkatkan.

IKM yang diperoleh PPSDMA sebaiknya dipertahankan dan terus ditingkatkan, yaitu melalui berbagai inovasi produk, inovasi layanan, inovasi proses, inovasi pasar, dan inovasi organisasi (Varis \& Littunen, 2010). Untuk memulai proses inovasi, PPSDMA harus mengetahui stating point-nya agar dimensi inovasi yang akan dilakukan menjadi terarah dan jelas. Pada kondisi saat ini, stating point dimensi inovasi PPSDMA belum diketahui, sehingga dilakukan penelitian ini. Dimensi strategi inovasi juga perlu diketahui, mana yang mendapatkan skor maksimal dan minimal sehingga PPSDMA akan mudah dalam memetakan dimensi strategi inovasi dan fokus pada dimensi strategi tersebut. 


\section{Tinjauan Pustaka}

\section{a. Konsep Kepercayaan Publik (public trust)}

Elemen dari kepercayaan meliputi beberapa hal, diantaranya:

Komitmen yang kredibel, kompetensi, kerja sama, kepedulian terhadap orang lain, responsivitas, komunikasi, keterbukaan, komitmen, tidak memanfaatkan yang lain (tidak oportunisme), berperilaku etis, penanganan yang sama, prediktabilitas (pertahankan kata-kata), akuntabilitas, dan keandalan. Kepercayaan pada pemerintah telah diidentifikasi sebagai salah satu fondasi terpenting sebagai legitimasi dan keberlanjutan sistem politik yang dibangun. Kepercayaan sangat penting untuk kohesi sosial dan kesejahteraan karena hal itu memengaruhi kemampuan pemerintah untuk memerintah dan memungkinkan mereka untuk bertindak tanpa paksaan. Hal ini merupakan cara yang efisien untuk menurunkan biaya transaksi dalam hubungan sosial, ekonomi dan politik (OECD \& OECD, 2013)

Menurut (Sayavaranont \& Piriyasurawong, 2019) tingkat kepercayaan yang tinggi pada pemerintah dapat meningkatkan efisiensi dan efektivitas operasi pemerintah. Supporting pemerintah terhadap innovasi e-goverment berkorelasi dengan kepercayaan publik (Horsburgh et al., 2011).

\section{b. Teori inovasi}

Peningkatan kinerja organisasi memerlukan perubahan yang bersifat strategis. Business as usual dari sebuah organisasi tidak lagi sesuai pada masa sekarang ini. Menurut (Sartika, 2015) jika organisasi ingin meningkatkan produkstivitas, efisiensi memelukan konsep berfikir dan tindakan yang inovatif. Inovasi bisa meliputi produk atau layanan, maupun model bisnis yang baru.

Peningkatkan daya saing (competitiveness) sebuah organisasi perlu dilakukan penyesuaian antara orientasi pasar, dan juga strategi inovasi (Kaliappen \& Hilman, 2017)

Inovasi merupakan pemicu agar sebuah organisasi menjadi sukses dan berkelanjutan. Kreatif dan fokus pada inovasi merupakan kunci dari kemenangan dalam rangka kompetisi dengan pihak kompetitor. Ada enam strategy desain yang umum digunakan untuk membangun inovasi di sebuah produk (Hsu, 2017), yaitu:

- Memperbaiki desain produk dan meningkatkan prosedur

- Meningkatkan kualitas produk

- Meningkatkan nilai tambah produk

- Mengurangi biaya produksi

- Simplifikasi proses dan pemeliharaan.

- Meningkatkan marketing dan kemampuan adaptasi.

Saat ini berbagai industri, baik jasa maupun produk barang melakukan konfrontasi saat global ekonomik sekarang ini, termasuk provider training mengalami berbagai tantangan akibat adanya efek globalisasi, bertambahnya rival, perubahan teknologi yang begitu cepat, perubahan lingkungan yang fluktuatif dan harapan pelanggan yang terus meningkat. Setiap faktor strategi memiliki potensi yang cukup besar untuk menghadapi masalah yang ada oleh provider training. Kesalahan dalam pengambilan keputusan akan menjerumuskan ke dalam kondisi yang relatif sulit. 
Menurut (Zuñiga-Collazos et al., 2019) strategi kompetitive generik memajukan ide bahwa keunggulan kompetitif yang berkelanjutan tergantung pada tingkat nilai yang dihasilkan organisasi untuk para stakeholder. Berhadapan dengan tantangan yang terus bertambah disarankan menggunakan cost leadership dan diferensiasi strategi, yaitu dua strategi untuk menciptakan daya saing yang unggul. Lembaga training yang menerapkan strategi diferensiasi menganggap pelanggan sebagai prioritas pertama mereka. Loyalitas pelanggan merupakan hal utama, keunikan akan menciptakan keunggulan kompetitive yang berkelanjutan. Bahkan diferensiasi akan meningkatkan minat pelanggan untuk membeli dengan penawaran yang cukup tinggi. Dengan karakteristik strategi bersaing diatas maka jenis orientasi pasar dan strategi inovasi perlu dipertimbangkan.

\section{c. Tipe tipe inovasi di sektor publik}

Inovasi yang dilakukan oleh organisasi mengacu pada kondisi lingkungan organisasi tersebut, kondusif atau tidaknya untuk melakukan inovasi. Organisasi dapat melihat produk layanan organisasi pesaingnya dan memastikan layanan yang diberikan memiliki keunikan. Dalam penelitian ini, strategi inovasi akan terbagi menjadi tiga dimensi, yaitu inovasi teknologi, inovasi model bisnis, dan inovasi manajemen.(Hsu, 2017)

Inovasi diartikan sebagai "membuat perubahan pada sesuatu yang mapan dengan memperkenalkan sesuatu yang baru". Definisi ini tidak menyarankan bahwa ide di balik perubahan harus radikal atau harus terjadi secara eksklusif pada produk. Ide sering kali bersifat biasa dan inkremental dan dapat memengaruhi produk, proses, dan layanan di setiap level dalam suatu organisasi.(O'Sullivan \& Dooley, 2008)

Menurut (Varis \& Littunen, 2010) jenis inovasi meliputi inovasi produk, proses, market dan organisasi. Sedangkan menurut (O'Sullivan \& Dooley, 2008), terdiri dari inovasi produk, inovasi proses, dan inovasi layanan.

Inovasi produk adalah membuat perubahan pada produk fisik. Misalnya memperkenalkan ukuran layar baru di pesawat televisi, beralih dari televisi tabung lama ke televisi layar datar atau menambahkan fungsionalitas seperti akses internet ke televisi.

Inovasi proses adalah tentang membuat perubahan pada proses yang menghasilkan produk atau jasa. Misalnya membuat mesin baru yang merakit televisi, mendesain ulang perakitan saluran sehingga televisi dapat diproduksi lebih murah dan outsourcing produksi penutup plastik di televisi jadi agar biayaproduksi dapat dikurangi, dan kualitas ditingkatkan. Inovasi layanan adalah tentang membuat perubahan pada layanan bagi pelanggan menggunakan. Misalnya mengubah cara dealer menjual televisi untuk menjaga biaya tetap rendah, mengubah cara pelanggan menyingkirkan televisi lama mereka dengan memperkenalkan 'take back 'dan mengubah cara pelanggan membeli televisi melalui internet. Jelas, layanan belum tentu melibatkan produk. Layanan juga dapat dikembangkan sesuai kebutuhan informasi pemerintah, dan sebagainya (O'Sullivan \& Dooley, 2008).

Oleh karena itu, suatu organisasi perlu terus melakukan inovasi dalam pelayanan meningkatkan fitur layanan untuk memenuhi kebutuhan pelanggan. 


\section{d. Dimensi Strategi Inovasi}

Strategi organisasi seperti sebuah orkestra yang dikombinasikan antara penggerak inovasi internal organisasi dan penggerak ekternal organisasi (Teece, 2009). Internal organisasi diantaranya, yaitu kompetensi dan juga tingkat teknologi dari sebuah organisasi. Penggerak eksternal meliputi: perspective industri, pandangan customer.

Ada delapan dimensi strategi inovasi bagi sebuah organisasi (Group, 2002):

- Mengelola proses inovasi, kombinasi pendekatan strategi bisnis antara tradisional dengan non tradisional.

- Penyelarasan strategi, mengumpulkan dukungan internal.

- Pandangan industri kedepan, memahami tren yang muncul

- Wawasan pelanggan, memahami artikulasi dan non artikulasi kebutuhan pelanggan.

- Teknologi dan kompetensi inti, memberdayakan aset organisasi.

- Kesiapan organisasi, kemampuan untuk melakukan tindakan.

- Implementasi kedisiplinan, dari inspirasi ke impak bisnis

- Keberlanjutan inovasi, sebuah platform untuk menghadapi persaingan.

Banyak organisasi yang ingin lebih berinovasi, tetapi tidak tahu harus bagaimana untuk mulai berinovasi, sementara pikiran pertama yang jelas adalah untuk memperkenalkan "pelatihan kreativitas", efeknya biasanya berumur pendek, dan hanya ada sedikit dampak pada kesadaran organisasi. Seringkali, struktur internal organisasi, kebijakan dan budaya menghambat inovasi. Sebagian besar organisasi sudah menerapkan beberapa dimensi pendekatan Strategis Inovasi, meskipun sering kali secara ad hoc tanpa kerangka kerja yang menyeluruh. Jadi bagaimana sebuah organisasi dapat memajukan praktik inovasi saat ini dan bergerak lebih jauh di sepanjang jalan menuju Inovasi Strategis yang berkelanjutan?

\section{Metode Penelitian}

Penelitian ini dilakukan secara kuantitatif diawali dengan studi literatur sebagai landasan teori dalam melakukan penelitian inovasi di PPSDMA. Pengambilan data dilakukan melalui survey dengan menggunakan instrument pengukuran posisi framework inovasi yang telah digunakan oleh innovation group untuk membantu pengembangan inovasi di berbagai organisasi baik organisasi laba maupun nirlaba.

Skema 1. Alur fikir penelitian pengukuran stating point

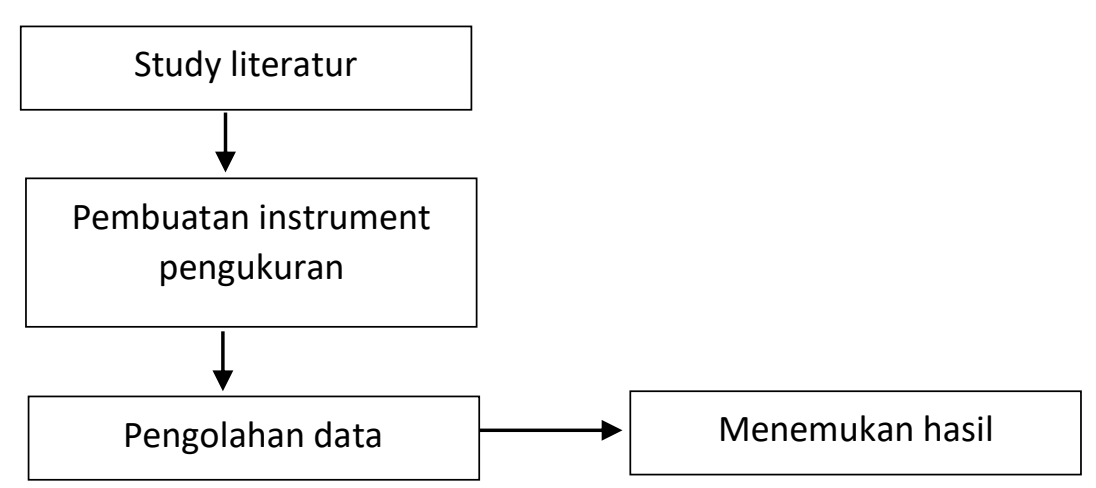


Pengambilan data dilakukan kepada seluruh pegawai PPSDMA yang selanjutnya diolah menggunakan statistic, sehingga didapatkan hasil yang digunakan sebagai Langkah analisis dan pemilihan strategy yang sesuai untuk pengembangan inovasi di PPSDMA.

Sampel dari populasi, terdiri dari beberapa anggota populasi. Proses ini diambil karena dalam banyak kasus tidak mungkin meneliti seluruh anggota populasi Ferdinand (2006). Tahapan selanjutnya adalah menentukan jumlah sampel dari populasi yang ada. Penentuan jumlah sampel menggunakan pendekatan statistik (traditional statistic model), didasarkan pada rumus formula statistik pendekatan Slovin (Tejada \& Punzalan, 2012):

$n=\frac{N}{1+N d^{2}}$

Keterangan :

$\mathrm{n}=$ jumlah sampel

$\mathrm{N}=$ ukuran populasi

$d=$ margin of error (5\%)

Jumlah populasi adalah 80 orang dan yang mengembalikan formulir quesioner sejumlah 71 responden, sedangkan validasi responden berdasar jumlah sampel yang dihitung adalah sebesar:

$$
\begin{aligned}
& n=\frac{80}{1+80(0.05)^{2}} \\
& \mathrm{n}=66,6
\end{aligned}
$$

Tabel 2. Kriteria Skoring PPSDMA sumber (Group, 2002)

\begin{tabular}{lll}
\hline Skoring & Kategori & Keterangan \\
\hline $\mathbf{3 , 5 0 - 4 , 0 0}$ & Strategic innovator & $\begin{array}{l}\text { Organisasi memahami elemen inti dari strategi inovasi } \\
\text { dan memiliki posisi yang baik untuk tetap menjadi } \\
\text { inovator terkemuka. Strategi Inovasi melekat dalam } \\
\text { budaya dan produk serta layanan baru mungkin } \\
\text { sudah memenuhi business process. } \\
\text { Apa selanjutnya? - Pastikan organisasi terus } \\
\text { mengantisipasi kebutuhan pelanggan, mengkanibal } \\
\text { produk dan layanannya sendiri, serta menetapkan } \\
\text { standar industri. Terus gabungkan pembelajaran dan } \\
\text { tentukan proses untuk inovasi berkelanjutan. }\end{array}$ \\
\hline $\mathbf{2 , 9 0 - 3 , 4 0}$ & Inspired innovator & $\begin{array}{l}\text { Organisasi mendemonstrasikan beberapa praktik } \\
\text { inovasi yang solid, tetapi ada area kelemahan. Jalur } \\
\text { bisnis proses mungkin penuh, meskipun peluang } \\
\text { terobosan ada kemungkinan kalah jumlah dengan } \\
\text { inovasi tambahan. Apa selanjutnya? - Fokus pada area } \\
\text { kelemahan dan mulai mendefinisikan proses untuk } \\
\text { inovasi berkelanjutan. }\end{array}$ \\
\hline $\mathbf{2 , 4 0 - 2 , 8 0}$ & Hopefullinnovator & $\begin{array}{l}\text { Percikan inovasi ada, meskipun hasil organisasi } \\
\text { mungkin condong ke perbaikan bertahap daripada } \\
\text { inovasi yang mengubah permainan. Begitu pula, }\end{array}$ \\
&
\end{tabular}




\begin{tabular}{|c|c|c|}
\hline & & $\begin{array}{l}\text { pendekatan organisasi mungkin bersifat ad hoc dan } \\
\text { tidak terstruktur. Apa selanjutnya? Mengambil } \\
\text { pandangan sistematis dari strategis inti, fokus pada } \\
\text { pelanggan, dan faktor organisasi yang diperlukan } \\
\text { untuk inovasi strategis dan segera mencari peluang } \\
\text { "capai yang mudah lebih dulu". Luangkan waktu } \\
\text { untuk memasukkan pembelajaran organisasi dan } \\
\text { mulailah menentukan proses untuk inovasi } \\
\text { berkelanjutan. }\end{array}$ \\
\hline$<2,30$ & $\begin{array}{l}\text { Challenged } \\
\text { innovator }\end{array}$ & $\begin{array}{l}\text { Meskipun organisasi anda menyadari bahwa inovasi } \\
\text { itu penting, budaya dan proses organisasi Anda tidak } \\
\text { mendukung Strategi Inovasi. Inovasi bersifat ad hoc } \\
\text { dan tidak terstruktur. Apa selanjutnya? - Dedikasikan } \\
\text { sumber daya untuk inisiatif inovasi berskala kecil dan } \\
\text { terfokus dengan hasil yang dapat diukur. Luangkan } \\
\text { waktu untuk memasukkan pembelajaran organisasi } \\
\text { dan mulailah menentukan proses untuk inovasi } \\
\text { berkelanjutan }\end{array}$ \\
\hline
\end{tabular}

Source: www.google.com

\section{Pembahasan dan Hasil}

Dimensi inovasi diukur menggunakan skala likert dengan skor 1 sampai dengan 4 dimana 1 sangat tidak setuju sedangkan 4 sangat setuju. Menurut strategic innovation group ada sepuluh area yang meliputi; mengelola proses inovasi, kombinasi pendekatan strategi bisnis antara tradisional dengan nontradisional; Penyelarasan strategi, mengumpulkan dukungan internal; pandangan industri ke depan, memahami tren yang muncul; wawasan pelanggan, memahami artikulasi dan non artikulasi kebutuhan pelanggan; teknologi dan kompetensi inti, memberdayakan aset organisasi; kesiapan organisasi, kemampuan untuk melakukan tindakan; implementasi kedisiplinan, dari inspirasi ke dampak bisnis; keberlanjutan inovasi, dan sebuah platform untuk menghadapi persaingan.

Kuesioner diberikan kepada seluruh pegawai PPSDMA, yaitu persepsi dari pegawai terhadap inovasi di organisasi PPSDMA. Kunci skoring menurut strategy innovation group, yaitu seperti terlihat pada tabel 2.

Pengolahan data dengan menggunakan program excell untuk mendapatkan statistik sederhana seperti dalam tabel 3.

Gambar 1. Grafik Nilai Dimensi Inovasi Organisasi PPSDMA 2020

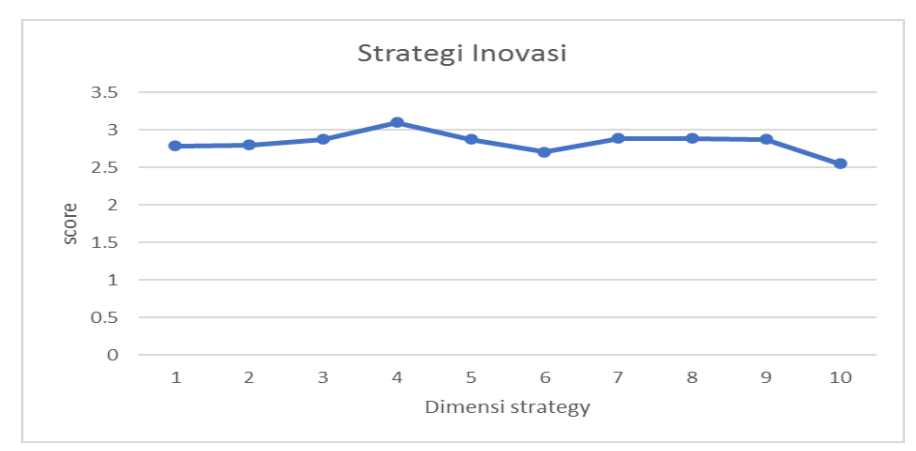


Hasil pengukuran inovasi organisasi PPSDMA dapat dilihat di gambar 1, nilai rata rata sekitar 2.83 artinya PPSDMA ada di baseline sebagai hopefull inovator ke inspired innovator. PPSDMA di dalamnya ada semangat inovasi, meskipun hasil organisasi mungkin condong ke proses continous improvement atau perbaikan bertahap daripada inovasi yang mengubah pola permainan business process. Begitu pula, pendekatan organisasi masih bersifat ad hoc dan tidak terstruktur. PPSDMA harus berani mengambil pandangan sistematis dari strategis inti, fokus pada pelanggan, dan faktor organisasi yang diperlukan untuk strategi inovasi dan segera mencari peluang "capai yang mudah lebih dulu". Luangkan waktu untuk memasukkan pembelajaran organisasi dan mulai menentukan proses untuk inovasi berkelanjutan.

Tabel 3. Data Hasil Dimensi Inovasi PPSDMA

\begin{tabular}{ll} 
Rata rata & 2,833802817 \\
\hline Minimal & 2,549295775 \\
\hline Maksimal & 3,098591549 \\
\hline Standar Deviasi & 0,141905243 \\
\hline Variant & 0,020137098 \\
\hline Modus & 2,873239437 \\
\hline Median & 2,873239437
\end{tabular}

Nilai minimal 2.54 sedang nilai maksimal 3.09 sehingga ada rentang nilai sebesar 0.55 . Standar deviasi sebesar 0.14 sehingga sebaran data tidak terlalu jauh dan tingkat akurasi cukup baik.

Pada tabel 3 juga dijelaskan nilai minimal pada point 2.54 yaitu pada kriteria produk baru dan pengembangan layanan, untuk menghadapi persaingan, artinya PPSDMA masih pada desain produk yang relatif monoton masih menunggu tersusunnya berbagai perangkat produk, sudah melakukan terobosan inovasi yang solid tetapi masih ada titik kelemahan yang perlu ditingkatkan. Perlu analisis lebih jauh untuk mengetahui variabel variabel yang mempengaruhi poin produk baru dan pengembangan layanan PPSDMA.

Nilai maksimal PPSDMA ada pada kriteria customer insight, yaitu 3.09 artinya PPSDMA merupakan organisasi yang mengutamakan pelanggan, tetapi masih kurang memahami perilaku, persepsi, dan kebutuhan pelanggannya sehingga perlu peningkatan lebih baik lagi. Keterlibatan pelanggan dalam pengembangan layanan yang menggunakan metode focus group discussion atau survey berbasis web atau training need analysis masih belum optimal, padahal terkadang forum yang sama juga digunakan untuk memunculkan kategori layanan yang baru, yaitu dengan menggunakan pendekatan generatif. Sebagai mitra sejati dalam proses inovasi, PPSDMA belum mengadopsi pendekatan wawasan pelanggan. "Customer Insight" dalam bentuk kualitatif, pendekatan "bottom-up" yang memanfaatkan wawasan tentang perilaku, persepsi dan kebutuhan pelanggan saat ini dan calon pelanggan dengan melibatkan mereka sebagai stakeholder utama dalam proses inovasi.

Perlu pendekatan kualitatif non-tradisional untuk penelitian pelanggan dalam mencari pemahaman mendalam tentang kebutuhan pelanggan dan pendorong perilaku pelanggan pada tingkat yang jauh melampaui apa yang dapat diartikulasikan oleh pelanggan itu sendiri (Group, 2002).

Pendekatan ini tidak terbatas pada pelanggan, tetapi dapat diperluas untuk mengumpulkan wawasan dari banyak jenis pemangku kepentingan lainnya - contohnya meliputi seluruh 
stake holder: mitra penyalur, pemasok, karyawan, unit institusi diatas PPSDMA, pengguna atau bukan pengguna.

\section{Diskusi}

Strategi inovasi berada di dasar piramida ekonomi sama seperti di pengembangan pangsa pasar: organisasi mencari celah dalam peta penentuan posisinya di industri; kemudian organisasi mengejarnya; dan memanfaatkan peluang tersebut. Tantangan umumnya berkaitan masalah keterjangkauan produk, penerimaan, ketersediaan dan kesadaran. (Anderson \& Markides, 2007). Kondisi ini sejalan dengan temuan didalam penelitian ini, yaitu dimana PPSDMA juga mengalami hal yang sama yaitu pada rendahnya point product dan service development, sehingga PPSDMA harus berusaha bahwa layanan yang diberikan kepada pengguna harus sesuai dengan harapan pelanggan, layanan harus berdasarkan survey secara benar melalui training need assesment.

Inovasi layanan membantu dalam mencapai beberapa tingkat customer satisfaction. Dengan demikian, inovasi layanan secara positif dan signifikan mempengaruhi customer satisfaction (Mahmoud et al., 2018). PPSDMA bisnisnya adalah jasa layanan diklat yang tentu saja proses berlangsungnya layanan akan sangat bersentuhan langsung dengan pengguna. Inovasi dalam layanan sangat dibutuhkan untuk memenuhi kepuasan pelanggan, produk dan layanan harus terus diinovasi secara berkelanjutan, sesuai dengan tuntutan industri 4.0 saat ini.

Inovasi merupakan aktivitas menciptakan produk atau layanan baru, proses teknologi baru, organisasi baru, atau peningkatan produk atau layanan yang sudah ada, proses peningkatan teknologi yang ada dan pengembangan organisasi yang sudah ada. Inovasi dapat diklasifikasikan: inovasi dalam produksi - pengembangan atau peningkatan produk tertentu; inovasi dalam layanan - menawarkan hal baru atau meningkatkan layanan yang sudah ada; inovasi dalam proses menemukan cara baru untuk mengatur dan menggabungkan masukan dalam proses produksi produk atau layanan tertentu; dan inovasi dalam manajemen menciptakan cara baru untuk mengatur sumber daya bisnis (Ramadani \& Gerguri, 2011). Kondisi ini juga sejalan dengan temuan dalam penelitian ini bahwa peningkatan dari strategi inovasi PPSDMA yang masih dipoint 2.83 yaitu dilevel hopefull innovator perlu ditingkatkan pada level yang lebih tinggi yaitu inspired innovator.

Membuat perubahan yang sesuai dalam layanan untuk mengangkat fitur persyaratan serta mencapai kinerja yang unggul dan keunggulan diferensiasi. (Kaliappen \& Hilman, 2017). Memunculkan produk layanan yang unik, peningkatan kinerja organisasi PPSDMA menjadi penting untuk terus digali, seperti dalam temuan dari penelitian ini, gap yang ada harus ditutup melalui strategi inovasi, salah satunya inovasi layanan dan produk yang masih menjadi titik lemah PPSDMA dan ini menjadi fokus organisasi agar segera dilakukan aksi nyata melalui aligment innovation organisasi.

\section{Simpulan dan Saran}

Proses adaptasi dari sebuah organisasi sangat penting karena kondisi yang terus berubah, begitu tidak menentu, komplek dan membingungkan, sehingga inovasi merupakan hal yang sangat penting. Inovasi tidak terlepas dari proses interaksi yang inherent antara teknologi, pasar dan organisasi. Demikian juga inovasi merupakan proses generik dari organisasi sehingga antara satu organisasi dengan organisasi lainnya akan menghasilkan kondisi yang 
berbeda akibat dari rutinitas yang berbeda juga. Hasil juga ditentukan oleh jenis teknologi yang digunakan antara organisasi satu dengan organisai lainnya. Rutinitas ini merupakan prosedur yang dilakukan oleh masing masing organisasi sehingga satu dengan lainnya akan sangat berbeda karena merupakan hal yang spesifik. Manajemen inovasi merupakan pencarian rutinitas yang efektif (Tidd \& Bessant, 2020), sehingga diperlukan pengelolaan dan proses pembelajaran yang terus menerus untuk mencari yang lebih efektif. Inovasi sukses tergantung pada dukungan organisasi, sehingga tingkat kematangan berinovasi dari sebuah organisasi perlu dilakukan pengukuran, agar dapat diketahui harus mulai dari mana sebuah organisasi bertindak, pengukuran maturitas inovasi bisa disa dilakukan pada kajian selanjutnya.

PPSDMA sudah berada pada point sebagai hopefull innovator dengan point rata rata 2.83, point yang harus ditingkatkan sebagai stating point bagi organisasi berdasar persepsi responden. PPSDMA harus mampu secara terus menerus mengantisipasi kebutuhan pelanggan, mengatur produk dan layanannya, serta menetapkan standar organisasi. PPSDMA sebaiknya mengambil pandangan sistematis dari strategis inti, fokus pada pelanggan, dan fokus pada faktor organisasi yang diperlukan untuk strategi inovasi dan segera mencari peluang "capai yang mudah lebih dulu". Terus menggabungkan pembelajaran dan tentukan proses untuk inovasi yang berkelanjutan.

Sebagai masukan bagi PSDMA setelah diketahui stating pointnya, maka perlu melakukan beberapa langkah ke depan, yaitu;

- Pengembangan produk dan layanan mendapatkan skor terendah, artinya organisasi PPSDMA berusaha untuk fokus dalam pengingkatan pelayanan dan pengembangan produk atau program yang akan dilaksanakan selanjutnya. Pencarian solusi dan pemenuhan kesenjangan sesuai dengan kondisi yang diinginkan

- Benchmarking yaitu melihat keluar oragnisasi, memahami best practise dari organisasi lain baik internal maupun ekternal bisnis organisasi.

- Langkah pengembangan dan adaptasi, menyusun proses pembelajaran yang baru dan relevan. Tanyakan sejauh mana organisasi bisa mengimplementasikan yang terbaik. Bagaimana organisasi PPSDMA bisa mengadopsi dan mengadaptasi best practice yang ada di luar organisasi.

- Langkah berikutnya, yaitu pelembagaan, sehingga semangat berinovasi menjadi kegiatan rutin di organisasi dan perbaikan secara terus menerus.

\section{Daftar Pustaka}

Anderson, J., \& Markides, C. (2007). Strategic innovation at the base of the pyramid. MIT Sloan Management Review, 49(1).

ESDM. (2016). Permen ESDM no 13 tahun 2016 tentang Organisasi dan Tata Kerja Kementerian ESDM.

Group, S. I. (2002). A framework for Strategic Innovation From Breakthrough Inspiration to Business Impact.

Horsburgh, S., Goldfinch, S., \& Gauld, R. (2011). Is public trust in government associated with trust in e-government? Social Science Computer Review, 29(2), 232-241.

Hsu, Y. (2017). Cocreation experiences: A strategic approach to product innovation and design. International Journal of Organizational Innovation (Online), 10(2), 106-126.

Joe, T., Bessant, J., \& Pavitt, K. (2005). Managing innovation: integrating technological, market and organizational change. John Wiley \& Sons.

Kaliappen, N., \& Hilman, H. (2017). Competitive strategies, market orientation types and innovation strategies: finding the strategic fit. World Journal of Entrepreneurship, 
Management and Sustainable Development.

Mahmoud, M. A., Hinson, R. E., \& Anim, P. A. (2018). Service innovation and customer satisfaction: the role of customer value creation. European Journal of Innovation Management.

O'Sullivan, D., \& Dooley, L. (2008). Applying innovation. Sage publications.

OECD, \& OECD. (2013). Trust in government, policy effectiveness and the governance agenda. Government at a Glance 2013.

Ramadani, V., \& Gerguri, S. (2011). "Theoretical Framework of Innovation: Competitiveness and Innovation Program in Macedonia." European Journal of Social Sciences, 23(2), 268276.

Sartika, D. (2015). Inovasi organisasi dan kinerja organisasi: Studi kasus pada pusat kajian dan pendidikan dan Pelatihan Aparatur III Lembaga Administrasi Negara. Jurnal Borneo Administrator, 11(2).

Sayavaranont, P., \& Piriyasurawong, P. (2019). Virtual Community of Practice using Human Performance Technology to Enhance Innovation Competency and Innovation for High Performance Organization. TEM Journal, 8(4), 1461-1468. https://doi.org/http://dx.doi.org/10.18421/TEM84-51

Teece, D. J. (2009). Dynamic capabilities and strategic management: Organizing for innovation and growth. Oxford University Press on Demand.

Tejada, J. J., \& Punzalan, J. R. B. (2012). On the misuse of Slovin's formula. The Philippine Statistician, 61(1), 129-136.

Tidd, J., \& Bessant, J. R. (2020). Managing innovation: integrating technological, market and organizational change. Wiley.

Varis, M., \& Littunen, H. (2010). Types of innovation, sources of information and performance in entrepreneurial SMEs. European Journal of Innovation Management.

Zhang, Y., Khan, U., Lee, S., \& Salik, M. (2019). The influence of management innovation and technological innovation on organization performance. A mediating role of sustainability. Sustainability, 11(2), 495.

Zuñiga-Collazos, A., Castillo-Palacio, M., \& Padilla-Delgado, L. M. (2019). Organizational Competitiveness: The Conceptualization and Its Evolution. Journal of Tourism and Hospitality Management, 7(1), 195-211. 